28

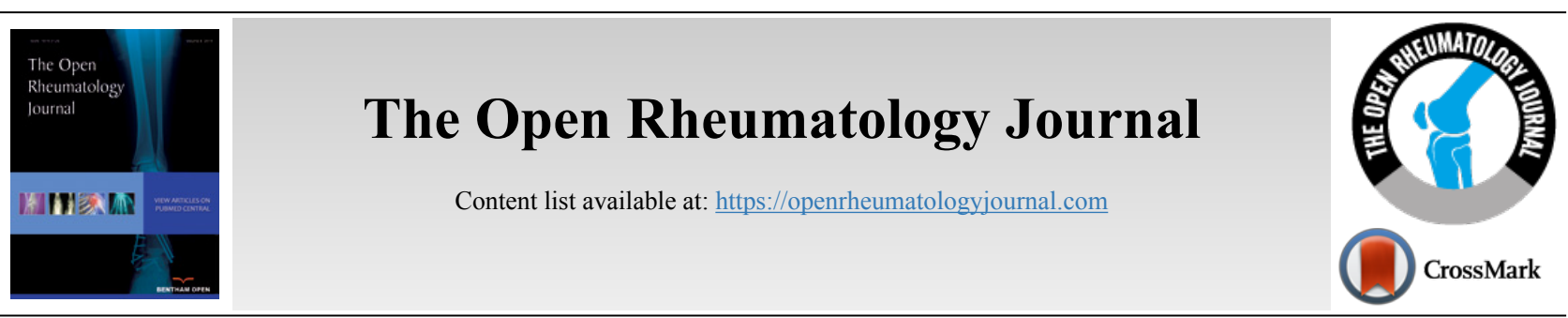

RESEARCH ARTICLE

\title{
Baricitinib in Rheumatoid Arthritis - Real World Cross-Sectional Study
}

\author{
Amol Sagdeo ${ }^{1}$, Ayman Askari ${ }^{1}$, Hana Morrissey ${ }^{2, *}(\mathbb{D})$ and Patrick A. Ball ${ }^{2}$ \\ ${ }^{1}$ The Robert Jones \& Agnes Hunt Orthopaedic Hospital NHS Foundation Trust, SY10 7AG, England, UK \\ ${ }^{2}$ School of Pharmacy, University of Wolverhampton, , WV1 1LY, England, UK
}

\begin{abstract}
:
Introduction:

Rheumatoid Arthritis (RA) is the most common cause of inflammatory polyarthritis. In RA, increased circulating levels of pro-inflammatory cytokines contribute to the overall symptomatology of fatigue, pain, and joint stiffness. Baricitinib is an orally administered biologic DMARD, used in RA patients, inhibiting signaling via JAK1/JAK2 inhibition, reducing the release of pro-inflammatory cytokines.

Objective:

To explore the efficacy and tolerability for baricitinib in a local population.

Methods:

A cross-sectional study was carried out to review data of RA patients on Baricitinib from the researchers' own clinic, since its approval in August 2017. The data was collected from an anonymized electronic patient records report. The clinical response was then classified into mild, moderate, and significant improvement.

\section{Results and Discussion:}

Overall, 27 out of 37 patients (72.9\%) showed clinical improvement with baricitinib. In $9(24.3 \%)$ out of 37 patients, the dose had to be reduced to either $2 \mathrm{mg}$ /day or $2 \mathrm{mg}$ /day - $4 \mathrm{mg}$ /day on alternate days. In four of the 9 patients' where the dose was reduced due to infections (UTI or sinuses), they subsequently experienced fewer infections while maintaining moderate improvement in their RA.

Conclusion:

There is a need for longer-term and larger studies to evaluate the full side effects profile of baricitinib in the local population.
\end{abstract}

Keywords: Rheumatoid arthritis, Janus associated kinase, Baricitinib, Conventional disease modifying drugs, Biologic disease modifying drugs, UTI.

Article History Received: June 16, 2020 Revised: September 03, 2020 Accepted: October 02,2020

\section{INTRODUCTION}

Rheumatoid Arthritis (RA) is the most common cause of inflammatory polyarthritis. In RA, increased circulating levels of pro-inflammatory cytokines contribute to the overall symptomatology of fatigue, pain, and joint stiffness. [ 1 ]. Rheumatoid Arthritis (RA) affects over 1\% of the population. RA synovitis affects the knees, ankles, hips, and shoulders, causing irreversible damage. However, as it progresses, it can also affect vital organs, such as the heart, lungs, and eyes [2].

Currently, rheumatoid arthritis is diagnosed by a combina-

* Address correspondence to this author at the School of Pharmacy, University of Wolverhampton, WV1 1LY, England, UK; E-mail: hana.morrissey@wlv.ac.uk tion of clinical presentation, imaging and blood tests, Rheumatoid Factor (RF), (less specific to RA), and anti-cyclic Citrullinated Peptides (anti-CCPs, specific to RA). When a patient with RA symptoms tests negative for the anti-CCPs, they may still be diagnosed using radiographic imaging [1].

Methotrexate (MTX), either alone or in combination with other conventional synthetic disease-modifying antirheumatic drugs (cDMARDs), remains the first-line therapy [3]. cDMARDs, such as oral methotrexate, leflunomide, or sulfasalazine, take up to 3 months to show benefit, necessitating short-term glucocorticoid therapy to induce remission. Approximately one-third of patients do not tolerate MTX treatment [4, 5]. Therefore, assessing therapies in 
development as alternatives to MTX is an important part of understanding potential new treatments [6]. When monotherapy fails to maintain remission or has unacceptable adverse effects, under the UK guidelines, the current next stage is a combination of conventional cDMARDs. Only when this has failed are biological agents considered. Biological agents can often provide effective monotherapy where patients cannot tolerate cDMARDS [1].

Multiple cytokines are implicated in the pathogenesis of RA and their release is partially mediated through the JAK-1/JAK-2 signaling pathway. JAK-1/JAK-2 heterodimer stimulates release of signaling molecules via a signal transduction pathway involving Signal Transducer and Activator of Transcription (STAT) proteins, which ultimately modulates gene expression in immunological cells. This modulates the release of interleukin- 6 and interferons. Baricitinib is an orally administered JAK-1/JAK-2 inhibitor that has shown efficacy and acceptable safety in patients with RA who had experienced an insufficient response to cDMARDs or other bDMARDs [ 7 - 9].

\section{METHODS}

This study was conducted in two parts: a mini critical review and a real-world retrospective data analysis. The retrospective data analysis study was considered as a process improvement audit by the National Health Service (NHS) Trust local research and development committee. Baricitinib was approved by the United Kingdom, National Institute for Health and Care Excellence (NICE) in August 2017, for use in moderate to severe RA in the following group of adult patients, where [10]:

[A] RA has responded inadequately to intensive therapy with a combination of cDMARDs, only if the disease is severe (a DAS-28 of more than 5.1).

[B] RA has responded inadequately to or who cannot have other DMARDs, including at least one bDMARD, only if the disease is severe (a DAS-28 of more than 5.1) and they cannot have rituximab.

[C] Baricitinib is used as monotherapy for people who cannot take methotrexate because it is contraindicated or because of intolerance when the criteria in sections 1 and 2 are met.
[D] To continue treatment only if there is a moderate response measured using European League Against Rheumatism (EULAR) criteria at 6 months after starting therapy. After an initial response within 6 months, withdraw treatment if at least a moderate EULAR response is not maintained.

In this retrospective study of 37 patients who received baricitinib between January 2017 and December 2019, the aim was to explore the outcome for these real-world RA patients, classified according to their response to the drug and side effect profiles experienced in this group of patients.

\section{MINI CRITICAL REVIEW}

To better understand the safety and efficacy of baricitinib, compared to other agents alone or in combination, such as adalimumab and baricitinib, with MTX or placebo, a literature search was conducted for randomized controlled clinical trials (Table 1 ).

Taylor et al. (2017) found that baricitinib and adalimumab were similar in safety in terms of increased infection rates, i.e., $36 \%$ and $33 \%$, respectively, compared with slightly lower infection risk in the placebo group of $27 \%$. Both medications were associated with lower levels of neutrophil count and the increasing infection risk. Both baricitinib and adalimumab increased cholesterol levels, however, only 2 patients in the baricitinib group and 1 patient in the adalimumab group experienced a serious cardiovascular event. There were five reported deaths; one was in the placebo group, two in the baricitinib group, one in the adalimumab group, and another patient in the placebo group who received rescue treatment with baricitinib [11, 12]. After week 12, baricitinib appeared slightly more effective in $70 \%$ of the patients on the American College of Rheumatology (ACR) scale - ACR20 measuring a $20 \%$ improvement on the 28 point scale, compared with $61 \%$ for adalimumab and $40 \%$ for placebo. In addition, a significant reduction in radiographic progression of structural joint damage was observed at weeks 24 and 52 for both baricitinib and adalimumab compared to placebo. The mean change in disease Disease Activity Score C-Reactive Protein activity score (DAS-28-CRP) at week 12 (-2.24 for baricitinib vs. -1.95 for adalimumab) suggests that baricitinib may be superior to adalimumab $[13,14]$.

Table 1. Summary of clinical trials included.

\begin{tabular}{|c|c|c|c|c|c|}
\hline Study & Intervention & Baricitinib Dose & \begin{tabular}{|c|} 
Duration \\
(Weeks)
\end{tabular} & Biologic Naive & Number of Participants \\
\hline 6 & $\begin{array}{l}\text { Baricitinib alone } \\
\text { vs. Baricitinib + Methotrexate } \\
\text { vs. Methotrexate alone }\end{array}$ & $4 \mathrm{mg}$ & 52 & Yes & $\begin{array}{c}\mathrm{N}=588 \\
213 \text { methotrexate } \\
106 \text { baricitinib } \\
213 \text { combination }\end{array}$ \\
\hline 11 & Adalimumab vs. Baricitinib vs. Placebo & $\begin{array}{c}40 \mathrm{mg} \\
4 \mathrm{mg}\end{array}$ & 52 & Yes & $\begin{array}{c}\mathrm{N}=1307 \\
490 \text { placebo } \\
490 \text { baricitinib } \\
326 \text { adalimumab }\end{array}$ \\
\hline 12 & Baricitinib vs. placebo & $2 \mathrm{mg}$ or $4 \mathrm{mg}$ & 24 & $\begin{array}{c}\text { No (but off biologic for } 4 \text { weeks wash } \\
\text { out prior enrolment) }\end{array}$ & $\begin{array}{c}\mathrm{N}=527 \\
175 \text { baricitinib } 2 \mathrm{mg} \\
175 \text { baricitinib } 4 \mathrm{mg} \\
175 \text { placebo }\end{array}$ \\
\hline
\end{tabular}


The addition of oral baricitinib as an add-on-therapy to oral MTX was associated with improvements in signs and symptoms, physical function, patient-reported outcomes, and progression of structural joint damage, as compared to placebo. It was also associated with improvements in ACR-20 response and DAS-28-CRP as compared to adalimumab [13, 14]. Fleischmann et al. (2017) and Genovese et al. (2016) compared the efficacy of baricitinib to adalimumab, concluding that baricitinib demonstrated superior ACR-20 response and DAS-28-CRP. Their evaluated end-point measures, after adjustment for multiplicity, included $20 \%$ improvement according to the criteria of the ACR-20 response (the primary end point), the Disease Activity Score for 28 joints (DAS-28), the Health Assessment Questionnaire-Disability Index, and the Simplified Disease Activity Index at week 12. In addition, the radiographic progression of joint damage was measured by the van der Heijde modification of the total Sharp score (mTSS) (range, 0 to 448, with higher scores indicating greater structural joint damage) at week $24[13,14]$. Results from the three studies are illustrated in Table 2.

\section{REAL-WORLD DATA RETROSPECTIVE STUDY}

This retrospective study included medical records for all adult RA patients receiving baricitinib, managed by the Rheumatology clinics at a District General Hospital in the UK Midlands. All patients had been diagnosed according to the
ACR/EULAR 2010 criteria [ 15 ]. The data was collected using an anonymized electronic patient records report, which is classified as a quality improvement process by the hospital Research and Development committee, not requiring ethical approval. The demographic data and clinic letters were used to assess the patients' clinical responses to baricitinib. Clinical improvement was inferred from multiple descriptors in the clinic records, which included DAS-28 score changes, patient's global assessment and/or physician's global assessments. The clinical response was classified into mild, moderate, and significant improvement as defined below:

[A] Mild improvement was defined as where a patient showed improvement in global assessment but no major improvement in their DAS-28 scores or physician's global assessment.

[B] Moderate improvement was when global assessment and physicians' global assessment showed improvement in DAS-28 score as per EULAR response criteria.

[C] Significant improvement was when a patient remained in remission or low disease activity state.

Of the 37 patients' records reviewed, there were $7(18.9 \%)$ males and $30(81 \%)$ females. Age distribution is illustrated in Fig. (1).

Table 2. Key findings of the trials.

\begin{tabular}{|c|c|c|c|c|c|c|c|c|c|}
\hline- & \multicolumn{3}{|c|}{ Study 6} & \multicolumn{3}{|c|}{ Study 10} & \multicolumn{3}{|c|}{ Study 11} \\
\hline - & Methotrexate* & Baricitinib* & $\begin{array}{c}\text { Combination } \\
\text { methotrexate } \\
\text { Baricitinib* }\end{array}$ & Placebo* & Baricitinib* & Adalimumab* & $\begin{array}{c}\text { Baricitinib } \\
2 \mathrm{mg} *\end{array}$ & $\begin{array}{c}\text { Baricitinib } \\
\text { 4mg* }\end{array}$ & Placebo* \\
\hline $\begin{array}{l}\text { DAS-28, } \\
\text { CRP }\end{array}$ & $5.9 \pm 1.0$ & $5.9 \pm 1.0$ & $5.9 \pm 0.9$ & $5.7 \pm 1.0$ & $5.8 \pm 0.9$ & $5.8 \pm 0.9$ & $5.9 \pm 0.9$ & $6.0 \pm 0.9$ & $5.9 \pm 1.0$ \\
\hline $\begin{array}{l}\text { DAS-28, } \\
\text { ESR }\end{array}$ & $6.6 \pm 1.0$ & $6.6 \pm 1.1$ & $6.6 \pm 1.0$ & $6.4 \pm 1.0$ & $6.5 \pm 0.9$ & $6.4 \pm 1.0$ & $6.6 \pm 0.9$ & $6.7 \pm 1.0$ & $6.6 \pm 1.1$ \\
\hline $\begin{array}{l}\text { Simplified } \\
\text { Disease } \\
\text { Activity } \\
\text { Index } \\
\text { (SDAI) }\end{array}$ & $42 \pm 14$ & $43 \pm 14$ & $43 \pm 13$ & $40 \pm 13$ & $40 \pm 13$ & $40 \pm 13$ & $43 \pm 14$ & $45 \pm 14$ & $42 \pm 14$ \\
\hline $\begin{array}{c}\text { Efficacy } \\
\text { (ACR-20 } \\
\text { response at } \\
\text { primary end } \\
\text { point)** }\end{array}$ & \multicolumn{3}{|c|}{$\begin{array}{r}\text { "The ACR20 response rate at week } 24 \text { for } \\
\text { baricitinib monotherapy and MTX monotherapy } \\
\text { was } \\
77 \% \text { and } 62 \% \text {, respectively }(P=0.001 \text { for } \\
\text { noninferiority). } \\
\text { Moreover, baricitinib monotherapy was found to } \\
\text { be superior to MTX monotherapy at week } 24 \\
(P=0.01) \text { ") }\end{array}$} & \multicolumn{3}{|c|}{$\begin{array}{r}\text { "At week 12, the primary ACR20 response } \\
\text { rate for } \\
\text { baricitinib was } 70 \% \text { as compared with } 40 \% \\
\text { for } \\
\text { placebo }(P<0.001) \text {. Significant } \\
\text { improvements with baricitinib as compared } \\
\text { with placebo were seen Baricitinib was } \\
\text { found to be significantly superior to } \\
\text { adalimumab }(P=0.01) "\end{array}$} & \multicolumn{3}{|c|}{$\begin{array}{r}\text { "At week } 12 \text {, the ACR20 response } \\
\text { rate (primary } \\
\text { end point) was } 55 \% \text { among patients } \\
\text { who received } \\
\text { baricitinib at a dose of } 4 \mathrm{mg} \text {, as } \\
\text { compared } \\
\text { with } 27 \% \text { among those who received } \\
\text { placebo } \\
(P<0.001 . \text { The } 2-m g \text { dose of } \\
\text { baricitinib was not compared with } \\
\text { placebo" }\end{array}$} \\
\hline
\end{tabular}




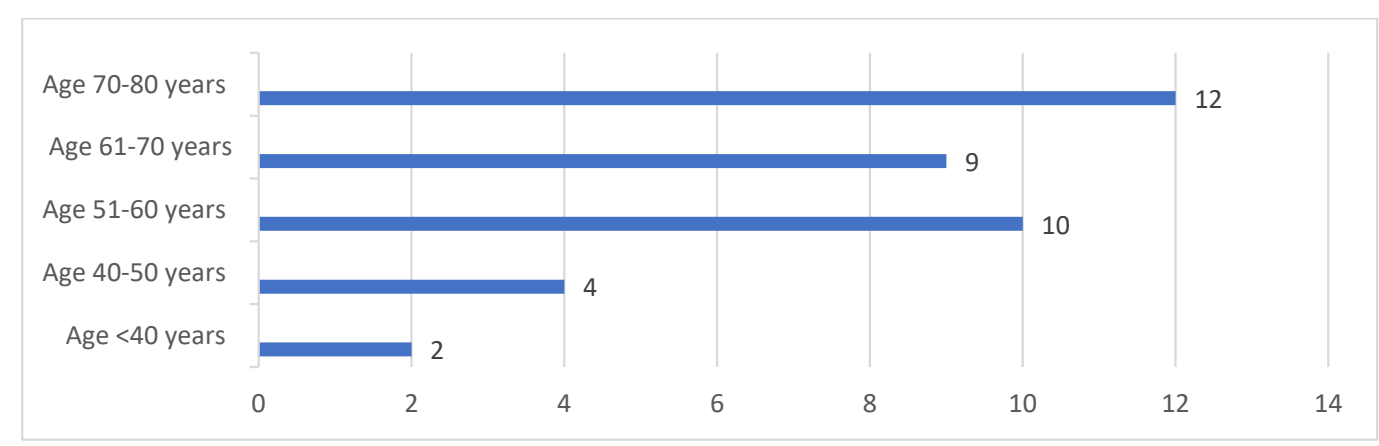

Fig. (1). The age distribution of the patients in this study.

Two patients (5.3\%) had been diagnosed with RA between five and ten years, whilst the majority of patients 34 (92\%) had been diagnosed for more than 10 years and one patient $(2.7 \%)$ for more than 20 years. Eight $(21 \%)$ had no comorbidities, while the remaining $29(78 \%)$ had one or more. Common comorbidities were type II diabetes, Chronic Obstructive Pulmonary Diseases (COPD), asthma, secondary osteoarthritis, osteoporosis, hypertension, Crohn's disease, IBS, Coeliac disease, Chronic Kidney Disease (CKD), fibromyalgia, anemia, peptic ulcer disease, recurrent Urinary Tract Infection (UTI), degenerative spine disease, hypothyroidism, and Interstitial Lung Disease (ILD). Seventeen patients (45\%) were on one or more additional cDMARD.

\subsection{Overall Impact and Efficacy of Baricitinib in all Patients with RA}

Where baricitinib was added on to a cDMARD or replaced the cDMARD, $8(21.6 \%)$ reported significant improvement, 17 $(45.9 \%)$ had moderate improvements, and $3(8.1 \%)$ had mild improvement. Eight (21.7\%) patients stopped treatment due to side effects and one patient prescribed baricitinib did not start therapy (2.7\%). Consequently, 28 out of 37 patients $(72.9 \%)$ showed clinical improvement with baricitinib.

In the 17 patients prescribed with baricitinib added to their current cDMARD's, 5 (29.4\%) demonstrated significant improvement, 8 (47\%) had moderate improvement, 2 (11.8\%) had mild improvement while $2(11.8 \%)$ patients out of those 17 stopped treatment due to side effects.

In the $19(51.3 \%)$ patients who received baricitinib as monotherapy, 3 (15.8\%) had significant improvement, 9 (47.3\%) had moderate improvement, and 1 (5.3\%) had mild improvement. Of these, 6 patients $(31.6 \%)$ had to cease baricitinib due to side effects.

The one patient who received baricitinib as first-line treatment had chronically abnormal Liver Function Test (LFT's) results at the time of diagnosis and did not wish to receive injections. All other patients had been previously exposed to one or more conventional or bDMARD's and had either found them ineffective or experienced unacceptable side effects.

\subsection{Baricitinib Safety and Side Effect Profile}

Side effects were experienced in $18(48.7 \%)$ of patients. Infections were noted in 10 patients (27\%). Recurrent UTI was the most common, followed by upper respiratory infections and sinusitis. GI side effects and neutropenia were noted in 3(8.1\%) and $2(5.4 \%)$ cases, respectively. One $(2.7 \%)$ of the patients who developed neutropenia and thrombocytopenia was also on leflunomide $20 \mathrm{mg}$ daily while the other patient had experienced neutropenia with leflunomide previously. One $(2.7 \%)$ of the patients reported severe headaches, which improved on stopping baricitinib and resumed when baricitinib was restarted after 6 weeks, hence baricitinib had to be ceased. Generalized erythematous rash was noted in $2(5.4 \%)$ patients, and a rise in serum cholesterol was noted in only $1(2.7 \%)$ patient.

\subsection{Tolerability of Baricitinib}

Most of the patients in this study tolerated baricitinib well. The longest duration of treatment amongst the patients reviewed was 29 months, while the shortest was 5 days. Out of the 37 cases, 5 (13.5\%) patients had baricitinib for $>24$ months, 17 (45.9\%) had it between 12-24 months, 4 (10.8\%) had it for 6-12 months. Only $10(27.1 \%)$ received it for $<6$ months and $1(2.7 \%)$ did not commence therapy. Five out of 37 patients had to discontinue baricitinib due to recurrent problems within six months of initiation and three patients discontinued therapy within one month. The main reasons for discontinuation of Baricitinib within 1 month were as follows:

[A] One of the patients developed neutropenia in 3 weeks and low platelets after commencing baricitinib. This was repeated on re-challenge, therefore a decision was made to stop its administration.

[B] One patient had easy bruising and fatigue after starting baricitinib and had to stop on the $6^{\text {th }}$ day.

[C] One patient developed lobar pneumonia needing admission within a month. This patient had a similar problem with other bDMARD's like etanercept, abatacept, and sarilumab.

\subsection{Lower Dose of Baricitinib}

In $9(24.3 \%)$ patients, the dose had to be reduced, either to 
$2 \mathrm{mg}$ /day every day or $2 \mathrm{mg} /$ day and $4 \mathrm{mg}$ /day on alternate days. In four of these nine patients, the reduction was due to infections (UTI or sinuses), and on the reduced dose, they experienced fewer infections while still maintaining moderate improvement in their RA. One of the patients experienced worsening $\mathrm{CKD}$ and another developed neutropenia on the $4 \mathrm{mg}$ /day dose but remained stable on a $2 \mathrm{mg}$ /day dose.

\section{RESULTS AND DISCUSSION}

Baricitinib was effective in $27(72.9 \%)$ of the 37 patients reviewed, which was similar to the findings in the three papers reviewed $[6,11,12]$. This efficacy was similar to the $70 \%$ ACR-20 efficacy in RA-BEAM data found by Genovese et al. (2016) [12]. In this study, baricitinib was used as an add-on therapy in 17 patients and as monotherapy in 19 patients. When used as a monotherapy, $12(63.15 \%)$ had a significant or moderate response. This correlates well with the RA-BUILD data, showing $62 \%$ ACR 20 response versus placebo [14]. In the RA-BEYOND study, it was noted that a reduced dose of baricitinib was associated with a lower rate of serious infections. It was also found that, out of nine patients in whom the dose was reduced, $4(44 \%)$ cases had a lower rate of infections while maintaining the efficacy [14]. The British National Formulary listed baricitinib side effects as dyslipidemia, herpes zoster outbreak, increase risk of infection, nausea, oropharyngeal pain, thrombocytosis, and venous thromboembolism [16].

Baricitinib was found useful in bDMARD naïve patients as well as in patients with inadequately treated or refractory RA with cDMARD. Being available in two strengths provided the option of reducing the dose in frail or elderly patients or patients with $\mathrm{CKD}$, as well as in patients experiencing frequent infections or neutropenia or GI side effects. Venous thromboembolism complications, in this study, were not noted but users need to be aware of the risk while following their patients in the clinics due to changes in lipids observed in patients undergoing baricitinib therapy [17].

\section{CONCLUSION}

In the rheumatology clinic population, baricitinib proved as a useful oral bDMARD, used as monotherapy or in combination with other CDMARD. There is a need for longerterm and larger studies to evaluate the full side effects profile of baricitinib, which is the limitation of this study.

\section{ETHICS APPROVAL AND CONSENT TO PARTICIPATE}

Not applicable.

\section{HUMAN AND ANIMAL RIGHTS}

Not applicable.

\section{CONSENT FOR PUBLICATION}

Not applicable.

\section{AVAILABILITY OF DATA AND MATERIALS}

Not applicable.

\section{FUNDING}

No external funding was received for any part of this study.

\section{CONFLICT OF INTEREST}

The authors have declared that no conflicts of interest exist.

\section{ACKNOWLEDGEMENTS}

The authors acknowledge the Colleagues of the Rheumatology department, who allowed us to review their patient data.

\section{REFERENCES}

[1] The National Institute for Health and Care (NICE). 2018.https://www. nice.org.uk/guidance/ng100

[2] Rheumatoid arthritis support network. RA Types: What distinguishes types of rheumatoid arthritis? https://www.rheumatoidarthritis.org/ ra/types/ [Accessed on May 2020];

[3] Aletaha D, Neogi T, Silman AJ, et al. 2010 Rheumatoid arthritis classification criteria: an American College of Rheumatology/ European League Against Rheumatism collaborative initiative. Arthritis Rheum 2010; 62(9): 2569-81.

[http://dx.doi.org/10.1002/art.27584] [PMID: 20872595]

[4] Fatimah N, Salim B, Nasim A, Hussain K, Gul H, Niazi S. Frequency of methotrexate intolerance in rheumatoid arthritis patients using methotrexate intolerance severity score (MISS questionnaire). Clin Rheumatol 2016; 35(5): 1341-5.

[http://dx.doi.org/10.1007/s10067-016-3243-8] [PMID: 27053094]

[5] Nikiphorou E, Negoescu A, Fitzpatrick JD, et al. Indispensable or intolerable? Methotrexate in patients with rheumatoid and psoriatic arthritis: A retrospective review of discontinuation rates from a large UK cohort. Clin Rheumatol 2014; 33(5): 609-14.

[http://dx.doi.org/10.1007/s10067-014-2546-x] [PMID: 24609758]

[6] Fleischmann R, Schiff M. Baricitinib, methotrexate, or combination in patients with rheumatoid arthritis and no or limited prior diseasemodifying antirheumatic drug treatment. Arthritis \& Rheumatology [online] 69;3: 506-17.https://onlinelibrary.wiley.com /doi/abs/10.1002 /art.39953 [Accessed Feb 20, 2020];

[7] Keystone EC, Taylor PC, Drescher E, et al. Safety and efficacy of baricitinib at 24 weeks in patients with rheumatoid arthritis who have had an inadequate response to methotrexate. Ann Rheum Dis 2015; 74(2): 333-40.

[http://dx.doi.org/10.1136/annrheumdis-2014-206478]

[PMID: 25431052]

[8] Tanaka Y, Emoto K, Cai Z, et al. Efficacy and safety of baricitinib in Japanese patients with active rheumatoid arthritis receiving background methotrexate therapy: A 12-week, double-blind, randomized placebo-controlled study. J Rheumatol 2016; 43(3): 504-11.

[http://dx.doi.org/10.3899/jrheum.150613] [PMID: 26834213]

[9] Genovese MC, Kremer J, Zamani O, et al. Baricitinib in patients with refractory rheumatoid arthritis. N Engl J Med 2016; 374(13): 1243-52. [http://dx.doi.org/10.1056/NEJMoa1507247] [PMID: 27028914]

[10] Baricitinib for moderate to severe Rheumatoid arthritis. Technology appraisal guidance [TA466] Published date: 09 August https://www. nice.org.uk/guidance/ta466/chapter/1-Recommendations2020.

[11] Taylor PC, Keystone E, van der Heijde D, et al. Baricitinib versus Placebo or Adalimumab in Rheumatoid Arthritis N Engl J Med [online] 376;7: 652-62.https://www.nejm.org/doi/full/10.1056/NEJ Moa1608345

[12] Genovese MC, Kremer J, Zamani O, et al. Baricitinib in patients with refractory rheumatoid arthritis. N Engl J Med [online] 374;13: 1243-25.

[http://dx.doi.org/10.1056/NEJMoa1507247]

[13] Dougados M, van der Heijde D, Chen YC, et al. Baricitinib in patients with inadequate response or intolerance to conventional synthetic DMARDs: Results from the RA-BUILD study. Ann Rheum Dis 2017; 76(1): 88-95.

[http://dx.doi.org/10.1136/annrheumdis-2016-210094] [PMID: 27689735] 
[14] Takeuchi T, Genovese MC, Haraoui B, et al. Dose reduction of baricitinib in patients with rheumatoid arthritis achieving sustained disease control: Results of a prospective study. Ann Rheum Dis 2019; 78(2): $171-8$.

http://dx.doi.org/10.1136/annrheumdis-2018-213271]

[PMID:
[15] Jonathan Kay, Katherine S. Upchurch, ACR/EULAR 2010 rheumatoid arthritis classification criteria Rheumatology 2012; 51(6): vi5-9.

[16] Joint Formulary Committee. In: British National Formulary.

[17] Taylor PC, Weinblatt ME, Burmester GR, et al. Cardiovascular safety during treatment with baricitinib in rheumatoid arthritis. Arthritis Rheumatol 2019; 71(7): 1042-55.

[http://dx.doi.org/10.1002/art.40841] [PMID: 30663869]

\section{C) 2020 Sagdeo et al.}

This is an open access article distributed under the terms of the Creative Commons Attribution 4.0 International Public License (CC-BY 4.0), a copy of which is available at: https://creativecommons.org/licenses/by/4.0/legalcode. This license permits unrestricted use, distribution, and reproduction in any medium, provided the original author and source are credited. 